\title{
Research on the Influencing Factors of Online Learning Satisfaction and Independent Learning of College Students
}

\author{
Zhang Le $^{1, a}$, Xi Yang ${ }^{2, b^{*}}$, Zhang Ying ${ }^{1, c}$ \\ ${ }^{1}$ Office of Academic Affairs, Beijing Institute of Fashion Technology, Beijing, China \\ ${ }^{2}$ School of Business, Beijing Institute of Fashion Technology, Beijing, China \\ a20180049@bift.edu.cn \\ b*13407008@qq.com, Corresponding author \\ c20120012@bift.edu.cn
}

\begin{abstract}
In the period of online teaching in 2020 , it is found that the platform use, course participation, teachers' teaching has a significant positive influence and correlation on college students' online learning satisfaction and independent learning from data analysis of 2235 student questionnaires. Multiple linear regression analysis indicates that compared with other variables, platform use has the biggest influence on learning satisfaction and independent learning. Based on research conclusion, this paper takes lessons from strengthening explore application of teaching platform, innovating management and service support of online teaching, enhancing level of teacher's online teaching, in order to provide a reference for future on online teaching and blending teaching.
\end{abstract}

Keywords: online learning, learning satisfaction, independent learning, multiple linear regression

\section{高校大学生线上学习满意度及自主学习影响因素研究}

\section{张乐 ${ }^{1, a}$ 席阳 ${ }^{2, b *}$ 张颖 $1, \mathrm{c}$}

${ }^{1}$ 北京服装学院教务处, 北京, 中国

2 北京服装学院商学院, 北京, 中国

a20180049@bift.edu.cn

b*13407008@qq. com, 通讯作者

20120012@bift. edu.cn

\section{摘要}

在 2020 年线上教学期间, 对 2235 份学生问卷进行数据分析显示, 平台使用、课程参与、教师教学对大学生 线上学习满意度及自主学习有着显著的正向影响和相关关系; 多元线性回归分析发现, 相较其他变量, 平台 使用对学习满意度和自主学习影响最大。基于研究结论, 从加强教学平台的探究运用、创新线上教学管理与 服务支撑、提升教师线上教学水平方面得到相应启示，为未来线上教学乃至混合式教学提供参考借鉴。

关键词: 线上学习, 学习满意度, 自主学习, 多元线性回归

\section{1.研究背景}

2020 年初爆发的新冠肺炎疫情，对全国乃至世 界高等教育带来了巨大冲击和挑战, 线下教育被迫
暂停，教育部发布“停课不停教、停课不停学”的号 召,全国高校相继开展线上教学。本次线上教学规模 之大、范围之广、程度之深, 是世界高等教育史上 前所未有的创举，“线上教学在全国高校的大范围展 
开，在我国高等教育历史上是第一次[1]。”根据厦门 大学教师发展中心发布的《疫情时期大学生线上学 习调查分析报告》 (以下简称《线上学习报 告》), 国内 334 所高校 118191 位被调查的大学生 中, $97.1 \%$ 的大学生参加了在线学习[2]。而据 2018 年数据统计, 我国高等教育领域中仅有 $27.7 \%$ 的学 生接受了网络学习, 在所有课程中网络课程数量仅 占 $5.5 \%[3]$ 。疫情防控期间线上教学保证了教育教学 秩序的同时迎来了发展契机, 其巨大优势为师生熟 知, 得到广泛的推广运用, 为未来教育教学改革发 展提供了强有力的支撑, 对人才培养具有重要意 义。

近年来, 线上学习已经成为大学生学习的重要 途径, 特别是 2020 年取得跨越式发展, 成为研究热 点。从线上学习受益主体一一学生的满意度来考察 线上学习的质量是一个重要的视角。比如沈忠华、 邬大光等对大学生在线学习成效及满意度的影响因 素探究发现, 知识建构、师生互动、信息处理对大 学生在线学习成效和满意度有着显著的正向影响 [4]。谭霞等对大学生线上英语学习满意度与持续学 习意愿影响因素研究发现 $80.57 \%$ 学生更倾向于现场 教学为主, 远程教学为辅 [5]。

已有研究还发现, 线上教学带来明显挑战就是 彰显了自主学习的重要性, 对学生的自主学习能力 提出了新要求。传统教学师生能够切身感受到课堂 的正式和庄严, 具有代入感, 而线上教学学生对教 师“只闻其声, 不见其人”, 缺乏校园学习氛围, 且 教师难以关注到网络另一端学生的上课状态, 因此 学生自主学习就成为线上学习效果的重要考量因 素。根据《线上学习报告》, 影响线上学习效果的 最主要因素 18 个方面的均值比较, 学生的自主学习 能力 (均值 4.13) 、良好线上学习行为习惯 (如按 时上课, 学习自律能力等) (均值 4.13) 为最高。 相关研究显示, 学生线上教学面对的困难中, 近四 成选择“面对电脑屏幕, 感到枯燥, 自主学习意识 差”, 可见学生学习的积极性和主动性较弱。且笔者 通过调研发现, 学生经历了一段时间线上教学后, 大多进入到疲㤂期, 学习主动性有所下降, 主要表 现为课前预习不到位、课上正点出勤率和到课率下 降, 有反复出入现象, 课后提交作业不积极, 没有 按时提交问题答案, 难以深度思考问题等。从实际 情况来看, 自主学习弱已经对线上学习产生一定负 面影响。

自主学习的学习思想由来已久。中外著名教育 家的教育理念中皆蕴涵着丰富的自主学习思想, 孔 子在两千多年前曾提出“授人以鱼不如授人以渔”, 表明了教师要教会学生学习方法。美国教育专家杜 威的“做中学”也提倡教师要教导学生学会学习。法 国自然主义教育思想家卢梭曾提出“良好教育的基本 原则和核心问题不在于告诉他一个真理, 而在于教 他怎样去发现真理”。自主学习是指个体自觉确定学 习目标、制定学习计划、选择学习方法、监控学习
过程、评价学习结果的过程或能力 [6]。本文认为自 主学习是学生在教师必要的指引、辅导和帮助下学 生积极、主动、自觉地从事和管理自己的学习活 动, 自己确定学习目标、选择学习内容和方法、监 控学习过程、评价学习结果的学习。

如果将线上学习满意度视为疫情下短期学生学 习评价的因素, 那么学生学习自主性这种长期、持 续性的活动即可视为中长期学习评价的考量。本文 从线上学习短期学习满意度与长期自主学习的角 度, 分析线上教学背景下大学生学习满意度和自主 学习的影响因素及影响程度, 以期未来提出相应改 进策略。

\section{2. 研究设计}

经历了 2020 年上半年的全面线上教学, 学生对 于线上学习已经较为熟悉, 为了解影响学生线上学 习满意度和自主学习的因素, 本研究设计了线上学 习体验问卷。问卷由基本情况、学习体验、对未来 混合式教学的建议三部分构成, 主要采取李克特 5 级量表, 考查学生对教学平台满意度、课程参与 度、对授课教师满意度、线上教学满意度、学习自 主性强弱。其中平台使用满意度、课程参与程度、 教师教学满意度为自变量, 线上学习满意度及自主 学习为因变量。问卷面向北京服装学院大一至大四 本科生, 于 2020 年 7 月回收有效问卷 2335 份。问 卷基本信息统计见表 1 。

表 1 问卷基本信息

\begin{tabular}{|c|c|c|c|}
\hline 题目 & 选项 & 人数 & $\begin{array}{c}\text { 百分比 }(\% \\
)\end{array}$ \\
\hline \multirow{2}{*}{ 性别 } & 男 & 366 & 15.67 \\
\hline & 女 & 1969 & 84.33 \\
\hline \multirow{4}{*}{ 年级 } & 大一 & 942 & 40.34 \\
\hline & 大二 & 658 & 28.18 \\
\hline & 大三 & 568 & 24.33 \\
\hline & 大四 & 167 & 7.15 \\
\hline \multirow{4}{*}{ 本学期上课门数 } & $1-5 门$ & 419 & 17.94 \\
\hline & 6-10门 & 1248 & 53.45 \\
\hline & 11-15门 & 600 & 25.7 \\
\hline & $\begin{array}{c}16 \text { 门及以 } \\
\text { 上 }\end{array}$ & 68 & 2.91 \\
\hline \multirow{4}{*}{$\begin{array}{c}\text { 平均每门课程使 } \\
\text { 用线上教学平台 } \\
\text { 数量 }\end{array}$} & 1 种 & 318 & 13.62 \\
\hline & 2 种 & 732 & 31.35 \\
\hline & 3 种 & 380 & 16.27 \\
\hline & $\begin{array}{c}4 \text { 种及以 } \\
\text { 上 }\end{array}$ & 905 & 38.76 \\
\hline
\end{tabular}


从基本情况来看, 回答问卷女生比例为 $84.33 \%$, 占据绝对优势, 由于学校是艺术类高校, 以女生为主, 此比例与实际基本吻合。年级以大一 为主, 比例为 $40.34 \%$ 。对于学生本学期上课门数, 超过半数 (53.45\%) 的学生选择“6-10 门”, 另有 $25.7 \%$ 的学生选择“11-15 门”。平均每门课程使用线 上教学平台数量, 选择“4 种及以上”接近 4 成, 选择 “3 种”比例为 $16.27 \%$, 可见半数以上学生使用平台 为 3 种及以上。具体各变量测量问卷题目如表 2 所 示。

\section{表 2 变量及相应的测量问卷}

\begin{tabular}{|c|c|}
\hline 变量 & 问卷题目 \\
\hline \multirow{4}{*}{ 平台使用 } & 平台稳定与流畅 \\
\hline & 平台和软件工具的功能 \\
\hline & 技术指导和服务支持 \\
\hline & 课程相关的平台资源 \\
\hline \multirow{5}{*}{ 课程参与 } & 出勤情况 \\
\hline & 课前预习 \\
\hline & 课上互动交流 \\
\hline & 课后作业与测试 \\
\hline & 课后与教师交流 \\
\hline \multirow{5}{*}{ 教师教学 } & 提供教学资源 \\
\hline & 课程设计与组织 \\
\hline & 期末考核 \\
\hline & 作业量 \\
\hline & 教学态度 \\
\hline $\begin{array}{c}\text { 线上教学满意程 } \\
\text { 度 }\end{array}$ & $\begin{array}{l}\text { 对本学期线上教学效果满意 } \\
\text { 程度 }\end{array}$ \\
\hline 自主学习 & $\begin{array}{l}\text { 经过本学期学习我总体上能 } \\
\text { 够自主学习 }\end{array}$ \\
\hline
\end{tabular}

对问卷的信度和效度进行测试分析。内部一致 性信度分析结果显示, 平台使用、课程参与、教师 教学维度的 Cronbach's $\alpha$ 值分别为 0.950、0.856、 0.928 , 各维度信度系数均高于 0.8 , 具有非常好的 信度。用因子分析探索此问卷的结构效度, 累积方 差贡献率为 $87.168 \% 、 83.836 \% 、 79.766 \%$, 每道题 在相应维度上的载荷值均高于 0.6 , 表明效度良好。 该维度划分的信度和效度均通过了检验, 说明具有 分析的意义和价值。

从自变量与因变量相关性分析发现, 平台使用 与学习满意度相关性最强, 其次是教师教学、课堂 参与; 课程参与和自主学习相关性最强, 其次是平 台使用、教师教学。

从自变量各个题目与因变量相关性分析来看, 所有题目均与线上教学满意程度呈正相关。具体来 看, 在平台使用变量中, 平台和软件工具的功能与 学习满意度相关性最强, 其它依次为: 技术指导和 服务支持、课程相关的平台资源、平台稳定与流
畅。在课程参与变量中, 课前预习与学习满意度相 关性最强, 其它依次为: 课上互动交流、课后与教 师交流、课后作业与测试、出勤情况。在教师教学 变量中, 课程设计与组织与学习满意度相关性最 强, 其它依次为: 期末考核、提供教学资源、教学 态度、作业量。

从自变量各个题目与因变量相关性分析来看, 所有题目均与自主学习呈正相关。具体来看, 在平 台使用变量中, 平台和软件工具的功能与自主学习 相关性最强, 其次为技术指导和服务支持、课程相 关的平台资源、平台稳定与流畅。在课程参与变量 中, 课前预习与自主学习相关性最强, 其它依次 为: 课上互动交流、课后作业与测试、课后与教师 交流、出勤情况。在教师教学变量中, 期末考核与 学习满意度相关性最强, 其它依次为: 课程设计与 组织、提供教学资源、教学态度、作业量。

进一步采用分层线性回归分析研究自变量对因 变量的影响。自变量为基本情况、平台使用、课程 参与、教师教学, 因变量为学习满意度和自主学 习。其中基本情况主要包括：性别、年级、本学期 上课门数、平均每门课程使用几种线上教学平台。

以自主学习为因变量的分层回归分析结果显 示, 平台使用相比基本情况、课堂参与和教师教学 对自主学习影响更大, 对自主学习的解释能力增加 了 $23.5 \%$ 。最终模型中, 平台使用、课程参与和教 师教学对自主学习有显著的正向影响（ $\mathrm{P}<0.001 ） 。$

\section{3.结论及启示}

\section{1 加强教学平台的探究运用}

作为线上教学得以实现的重要载体, 教学平台 对于线上教学的重要性居于首位。本文多元线性回 归分析也发现, 教学平台对学习满意度和自主学习 两个因变量的影响均是最大, 工欲善其事、必先利 其器, 应充分探究教学平台的优化与运用, 服务乃 至引领未来的教学改革。第一, 探索建立集中统 一、功能相对完备的教学平台。本文调研显示半数 以上学生平均每门课程使用线上教学平台数量为 3 种及以上，且不同课程使用不同平台，设备负荷 大，频繁切换平台也应接不㗇，因此亟需集中平台 软件选用数量。目前也存在师生熟悉常用的平台学 校系统不支持，或有些线上教学平台逐渐收费、限 制时长和人数, 给使用带来不便, 应根据师生对平 台需求，在统筹协调现有选用平台的基础上，结合 课程实际, 探索建立集中统一、功能相对完备的教 学平台。第二, 充分发挥平台的直播与录播优势, 直播与录播作为平台应有的两大功能, 应对二者取 长补短。直播使人身临其境、互动及时便捷; 录播 方便回放, 避免网络不畅, 二者相得益彰, 得到学 生青睐, 调研结果也显示, 未来学生希望采用线上 的授课形式，选择“直播+录播+交流群”的比例最 
高, 达到 59.06\%。第三，进一步完善平台互动交流 功能。充分利用多元化互动交流方式实现课堂高参 与度，不断完善如匿名投票、弹幕交流、签到考 勤、发起问卷、在线提问、屏幕共享、音视频交 流、课程资源共享、小组讨论等平台功能，多途径 增强师生交流与互动, 了解学生学习情况, 减少学 生在线学习孤独感和枯燥感, 形成师生之间, 生生 之间相互帮助、相互促进的良好学习环境。

\section{2 创新线上教学管理与服务支撑}

加强线上教学顶层设计和制度建设, 助力线上 课程持续发展, 为今后线上课程发展建设提供良好 政策引导与支持, 努力探索与线上教学相适应的管 理模式与管理方法。第一, 完善线上教学各环节, 规范线上教学具体方法和流程。实现资源丰富、交 互流畅、任务合理、考核及时、记录完整等线上教 学过程。在线学习效果评价注重学生之间的互评, 将师生交互、在线教学活动作为重要的评价内容。 提供有效的学习支持服务, 如资源更新、活动安 排、过程监督、问题的解决等支持服务, 以提升在 线学习效率。营造良好的线上学习环境和学习氛 围, 培养学生在线学习良好习惯和学习兴趣。第 二, 对教师开展线上教学针对性培训。注重教师信 息化思维养成, 引导教师利用信息化手段变革传统 课堂, 将教师网上指导、师生互动、作业批阅、学 情分析、答疑辅导等信息技术应用能力作为培训重 点。第三, 未来探索逐步推行线上和线下混合教 学。要基于课程性质和学科特点, 不同的课程其混 合的方式及比例、体现的教学成果都需要分门别类 地对待, 探讨每门课的最优教学模式, 先进行实 验, 再应用推广。目前来看, 理论课程、慕课比较 丰富和成熟课程, 适宜线上学习为主, 实验实践类 课程线下教学更为适合; 线上着重理论教学、观摩 赏析、慕课运用, 线下教学着重辅导答疑、重难点 解析、交流研讨、学生自学。此外, 优质网络资源 的篎选、整合及应用, 线上资源已十分丰富, 但是 千差万别又良莠不齐, 运用到实际教学中时需要有 准入监控和甄别, 特别是体现如课程思政等时代新 需求, 同时对于部分线上资源较少的艺术类课程, 尽快开展学校特色课程资源的线上建设, 对接和丰 富学校平台资源。

\section{3 提升教师线上教学水平}

线上教学对教师教学水平提出了要求和挑战, 应充分发挥线上教学优势, 以此为契机提升线上教 学水平。本研究发现, 教师的课程设计与组织与学 生学习满意度相关性最强, 在此方面应着重加强。第 一, 课前定期发布学习材料与计划、日程安排、学 习进度、论坛反馈等一系列提醒, 帮助学生便捷地 进行个人学习管理。第二, 课中寓教于乐, 增强课 程互动与趣味性, 授课精彩幽默的同时, 注重及时 互动与互动方式, 把握课程弹性节奏, 时间长短适 宜, 让学生在线上保持一种获取知识的兴奋状态。
第三, 课后考核, 本研究显示课程期末考核与自主 学习的相关性最强, 可见考核对于学生自主学习有 很大的导向性, 除了传统的闭卷考试, 探索其它考 核形式, 如作品展示展演、直播答辩等。其次, 适 当增强过程性评价, 如课堂互动讨论, 加分奖励均 可考虑纳入过程性考核。第四, 探索采取团队授课 模式, 多位教师切磋玩磨, 共同教授一门课。从实 际调研来看, $67.37 \%$ 的学生表示期待团队授课。线 上教学不受空间限制, 同一门课程建课程群, 共同 探索线上课程, 由主讲老师直播或录播, 其他教师 精讲或辅导答疑; 或多位教师分段录播或直播, 分 别辅导答疑。教师角色逐渐从知识传播者向学习促 进者和管理者转变, 尊重学生的主体性, 发挥学生 的主动性, 启发学生智慧思考, 促进学生深度学 习。

\section{项目基金}

本文为北京服装学院 2019 年教育教学改 革重点项目《以本为本，全面提升本科教育 质量背景下, 我校本科专业人才培养的研究 与实践》(ZDJG-1911)的阶段性成果之一。

\section{REFERENCES}

[1] Wu, D.G. (2020) The Retrospect and Reflection of Educational Technology Evolution: Online Teaching in Universities under the Epidemic Situation. China Higher Education Research, 36(04):1-6+11.

[2] Shen, Z.H., Wu, D.G. (2020) A Study on the Influencing Factors of Online Learning Effectiveness and Satisfaction of College Student: Empirical Analysis Based on Structural Equation Model. Research in Educational Development, 40(11):25-36+59.

[3] Fang, L. (2018) Research on the Current Situation, Question and Embedding Path of Online Teaching in Colleges. Marketing Research, 66(12):15-17.

[4] Shen, Z.H., Wu, D.G. (2020) A Study on the Influencing Factors of Online Learning Effectiveness and Satisfaction of College Student: Empirical Analysis Based on Structural Equation Model. Research in Educational Development, 40(11):25-36+59.

[5] Tan, X., Fu, Y.L. (2020) A Study on College Students' Online English Learning Satisfaction and Intention of Influencing Factors to Continue Learning. Technology Enhanced Foreign Language Education, 42(04):82-88+13.

[6] Pang, W.G. (2003) Evaluation Methods of Autonomous Learning. Journal of Psychological Science, 40(05):882-884. 